\title{
Task context changes: Teams' maladaptive responses to unanticipated change
}

Gamze Koseoglu (Corresponding Author)
Department of Management and Marketing
The University of Melbourne
Level 10, 198 Berkeley Street
Victoria 3010 Australia
Email: gamze.koseoglu.cosgun@gmail.com

Christina E. Shalley

Thomas R. Williams-Wells Fargo Professor of Organizational Behavior Area Coordinator

Scheller College of Business

Georgia Institute of Technology

800 West Peachtree St., N.W.

Atlanta, Georgia 30308

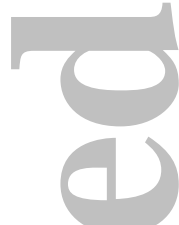

Email: Christina.shalley@scheller.gatech.edu

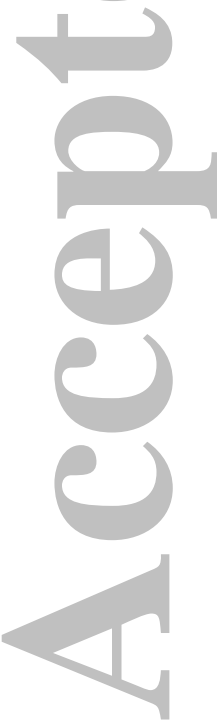

Benjamin Herndon

Director of Research, Analytics and Applied Statistics

The Internal Revenue Service

1111 Constitution Ave. NW Room 3017

Washington, D.C. 20004

Email: benjamin.d.herndon@irs.gov

This is the author manuscript accepted for publication and has undergone full peer review but has not been through the copyediting, typesetting, pagination and proofreading process, which may lead to differences between this version and the Version record. Please cite this article as doi:10.1111/ jasp.12424. 


\section{Task context changes: Teams' maladaptive responses to unanticipated change}

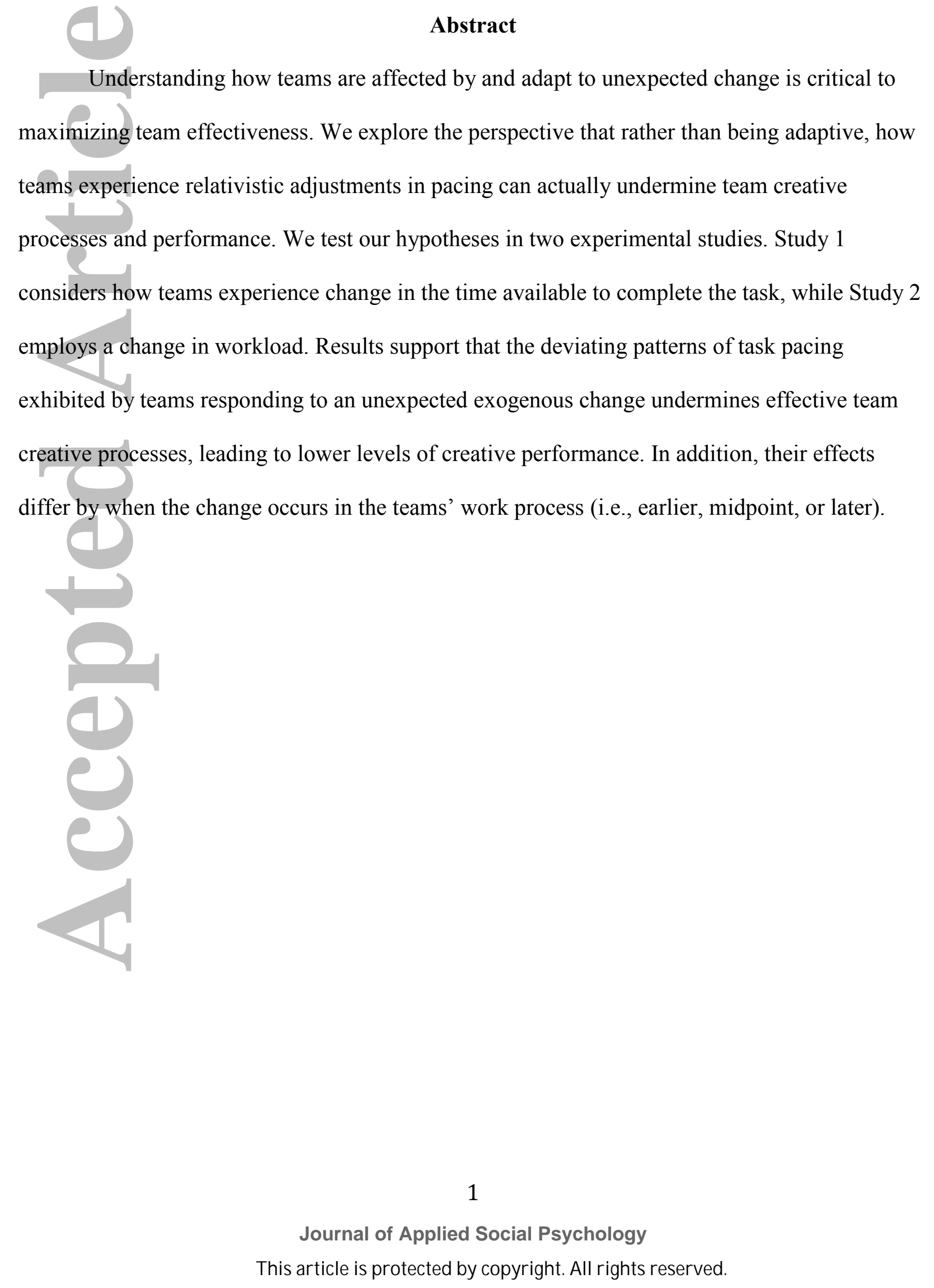


The work of modern organizational teams is often dynamic since midstream changes to task contexts are unavoidable as organizations respond to their competitive environments (Blount \& Janicik, 2001). Exogenous changes to a team's task context can take many forms, including changes in the resources available to a team, such as its membership (Lewis, Belliveau, Herndon, \& Keller, 2007) and the time allotted to complete a task (Ballard, Tschan, \& Waller, 2008), or changes to the context that add to or alter what is required to successfully perform the task (LePine, Colquitt, \& Erez, 2000). Regardless of whether task requirements or team resources or both are implicated in the changes, exogenous changes are generally understood to require teams to adapt in order to avoid adverse impacts on their performance (LePine, 2005; LePine, 2003; Waller, 1999).

Despite the prevalence of such changes in organizational life, we still have an incomplete picture of how they affect underlying team functioning. Most research perspectives maintain that the adverse effects of task context changes on team performance can be explained by teams' inability to adjust their activities by putting aside established task performance routines (Gersick \& Hackman, 1990) or by the states they experience as a direct result of these changes, such as heightened levels of time pressure (Baer \& Oldham, 2006) or job demands (Janssen, 2001). Successful teams are those that adapt when faced with changes to task context (Baard, Rench, \& Kozlowski, 2014; LePine, 2005; Randall, Resick, \& DeChurch, 2011). These perspectives ignore the possibility that teams can engage in adaptive responses that could turn out to be detrimental to team performance.

To address these gaps in the research on team adaptation, we look at how changes to task context affect the overall pattern of team performance, in particular, looking at behavioral patterns in how teams pace themselves over the full course of their work together. When teams 
work under stable conditions, in which they are not faced with exogenous changes in the task context, they work at a pace that slightly increases toward the deadline. However, an unexpected change in the task context can disrupt team pacing. We define deviating patterns of pace as the average deviation of team pace throughout the team process compared to the pace under stable conditions. These deviating patterns can help explain how teams maintain effective processes and ultimately how they perform. We argue that unanticipated, exogenous changes to the task context can result in deviating patterns of team pacing that have negative implications for team creative processes and performance. Furthermore, we introduce the exogenous changes at three different times: earlier in the teams' work process, at the midpoint, and later in their work process. In this way, we seek to examine the role of the timing of the exogenous change on deviating patterns of team pacing, team creative processes, and team creative performance.

This paper contributes to the literature on team change and adaptation in three ways. First, we look at deviating patterns of team pacing, and consider its effect on team processes and performance. The initial allocation of team resources, including time, may be somewhat arbitrary. For this reason, managers may infer that making midstream changes to a team's task requirements will have a negligible impact. Or they may infer that if the change has little impact on members' sense of time pressure, then the change will not have an adverse impact on team functioning. We maintain that both inferences are erroneous, and that the research presented here is necessary in order to understand just how changes to task context will affect team processes and performance. In doing so, we hope to encourage further inquiry into the dynamic interrelationship between team processes and task context.

According to previous research, changes that occur at the midpoint of teams' work process can influence teams' transition efforts the most (Gersick, 1989). Following this research 
stream, our second contribution to the literature is examining the role of the timing of the task context changes on team pacing, team creative processes, and team creative performance. Although teams are more likely to be vulnerable to change at the midpoint, some teams do not even experience a midpoint transition (Chang, Bordia, \& Duck, 2003; Gersick, 1989, Okhuysen \& Waller, 2002). Teams also can go through a linear progression of team developmental stages while working on a team task (Chang et al., 2003; Tuckman, 1985). Changes introduced at various points of the team developmental process can have different implications on performance. Yet, to our knowledge, the role of the timing of these changes on performance has largely been overlooked. We argue that it makes a difference when the exogenous change occurs in the teams' work process. Therefore, an exogenous change in and of itself can have an effect, but exactly when this change is introduced can have differential effects on the teams' processes and performance.

The midpoint is found to be a critical point in team functioning since teams tend to shift gears after the midpoint (Gersick, 1988; 1989). Yet, certain changes to task requirements might result in elimination of an actual perceived midpoint. Accordingly, in order to more completely examine the impact of task context changes we examine teams' responses to an exogenous change in two studies that consider the effect of two different types of task context changes: 1) changes to team resources, namely time, and 2) changes to their workload that affects whether they can successfully perform the task. When the time allotted for a task changes, team members cannot correctly perceive the midpoint. Therefore, while there is no actual midpoint in the first contextual change, there is a clear midpoint in the workload change situation. Hence, our third contribution is evaluating whether the introduction of exogenous changes have similar effects across different types of task context changes. 


\section{Creative teams}

We examine the effect of unexpected exogenous changes on team pacing and performance within the context of working on a creative task. The importance of creative and innovative teams to organizations cannot be overstated, making it critical that we understand how task context changes impact team creative performance. Creativity has been argued to be critical for organizational innovation and competitiveness (Yuan \& Woodman, 2010), and it has been proposed that examining team creative processes would be a fruitful approach to unlocking the creative potential of employees (Shalley, Zhou, \& Oldham, 2004). Teams are thought to be effective conduits for leveraging employees' exposure to diverse experiences and perspectives, while also creating a forum for the collective consideration and integration of these ideas (Gardner, Gino, \& Staats, 2012). Yet creative teams may be uniquely susceptible to the vagaries of dynamic environments, plagued by shifting organizational pressures and expectations that can complicate a team's ability to engage in creative processes and to deliver performance outcomes that are both novel and useful (i.e., creative).

Teams working on creative and innovative tasks provide an appropriate context to better understand the discretion that teams exercise with regard to pacing their work due to the nature of such tasks. First, team creative tasks are unique in that they are inherently ambiguous and nonlinear, as there is no predetermined sequence of work or cumulative effect of steps through which a team progresses in completing its goal. Team creative tasks are potentially highly iterative, as teams often return to work on an earlier point in the process in order to revisit it in light of current work or to make novel connections (Shalley \& Perry-Smith, 2008). As a result, there is little in the structure of a creative task to provide temporal referents by which a team might mark its rate of progress towards its goal. Second, there is no specified set of inputs to a 
creative task, nor specified process by which members' inputs are integrated. As a result of these unique qualities of creative tasks, teams cannot rely on the structure of the task to help determine milestones or appropriate pacing, leaving much greater discretion to the teams themselves. Team members also cannot rely on cues from the task context in developing useful temporal structures to guide their pace. Changes in work pace that result from task context change, therefore, are more likely to be driven by the psychological expectations of the team as opposed to being logically derived from the structure of the task itself.

Many of the seminal studies on pacing in teams have been conducted in creative task contexts. For example, Gersick (1989) looked at teams in the lab working on creating commercials for an airline company. While she did not study the rate of team work pacing per se, she did catalog time-pacing behaviors by which teams demonstrated that they were paying attention to time and their pacing. Results showed that teams increased their attention to time pacing at or near the midpoint and as they neared the deadline. Harrison and colleagues (2003) included creative tasks in their multitask study of team entrainment and pace. They measured speed (i.e. pace) by how long it took teams to complete the different tasks assigned. While such an approach would not allow researchers to capture changes in pace within a given task progression, it did allow them to demonstrate that the pace teams established on initial tasks persisted to subsequent tasks, showing teams' tendency to stick with initial pacing choices.

\section{Pacing}

How a team paces its performance activities over time is critical to performance, yet, our understanding of this and how it impacts team processes and performance is still nascent.

Gersick's studies of time in teams $(1988,1989)$ recognized that "groups must pace their use of a limited resource, time, in order to finish by the deadline" (1988; pp. 33-34). This description 
recognizes the two core components of pacing: 1) progression towards a 'temporal referent' and 2) the regulation of effort toward that end. A temporal referent is a point or range in time when an actor expects a certain outcome to be realized (Blount \& Janicik, 2001). While temporal referents can be influenced by other sources, such as an individual's proclivities with regard to the use and value of time or from non-work influences such as family or culture, it is temporal referents imposed by the task context that were the focus of Gersick's work and are of central interest in this paper.

The second component of pacing, the regulation of effort, is determined by allocating time to specific activities that need to be accomplished prior to reaching the temporal referent. Waller, Zellmer-Bruhn, and Giambatista (2002) distinguished two types of pace: 1) the rate at which task activities are performed, and 2) qualitative transitions in task focus. While there is significant research on the latter type of pace (Gersick, 1988, 1989; Karau \& Kelly, 1992), there is less research on the former type. To address this deficiency, our present research focuses on the rate at which task activities are performed. Our choice is also driven by our emphasis on longitudinal patterns of task activity, which are much easier to identify by tracking teams' pacing as opposed to the timing of periodic transitions in task activity.

Pacing functions a bit differently at the team level. When working on non-interdependent tasks, individuals can make unilateral pacing determinations, albeit influenced by the sources described above. However, team pacing also requires members to coordinate and synchronize collective efforts and regulate access to shared resources (Blount \& Janicik, 2001; Marks, Mathieu, \& Zaccaro, 2001). In teams, there is a transactional process by which 'temporal structures' are created that "guide, orient and coordinate ongoing activities" (Orlikowski and Yates, 2002; p. 684). It is important to note that pacing determinations can be implicit or explicit 
(Orlikowski \& Yates, 2002). Explicit pacing often takes the form of schedules that guide the allocation of temporal resources (Blount \& Janicik, 2001), whereas implicit agreement on pacing can emerge transactionally as the team develops shared knowledge about how to work together (Lewis, 2003; Rico, Sánchez-Manzanares, Gil, \& Gibson, 2008).

Considering the overall body of work on team pacing, there is not much empirical research that considers team pacing as the rate of effort. While Harrison and colleagues (2003) did look at the time it took for teams to complete a task, they did not really examine pace in terms of the way teams allocated time to performance activities. Other studies have considered pace in terms of attention to time (Waller et al., 2002). While this is clearly relevant to team pacing determinations, attention is not equivalent to the actual pace of work. Other studies of pace have relied on perceptions of time pressure (Jansen \& Kristof-Brown, 2005), which reflects whether teams perceive they have 'enough' time to complete the task, which is also not equivalent to pace as the rate of work. In one notable exception, Karau and Kelly (1992) studied the rate of task relevant statements exchanged between team members to capture pace of work. In this paper, we argue that considering how a team adapts the pace of its work activities over time is a useful way to understand how exogenous change effects team functioning. Where established team adaptation perspectives have only looked at how teams respond to change by engaging specific coping behaviors, a pacing-based perspective considers the central role of team performance activities themselves. Pacing is at the center of what Blount and Janicik (2001) call 'temporal responsiveness' which refers to “the ability of organizational actors to adapt their timing in response to unanticipated extra- and intra-organizational events" (Fine, 1998, p. 566), a critical form of organizational adaptation. Finally, pacing is a function of teams' shared, ongoing 
structures (Orlikowski \& Yates, 2002), and is a meaningful lens through which to understand how teams are affected by change.

In order to understand the patterns of work pace that result from unanticipated changes to task contexts, we first need to understand how stable patterns of team pacing emerge. Teams will make initial determinations about the pace at which they work based on their expectations regarding the requirements of the work they have to complete and the resources available to complete it, most notably in the form of time. Teams will allocate units of time to the performance activities that have to be completed. This forms a shared understanding among team members about how they will organize and pace their work together, guiding their activities over time (Orlikowski and Yates, 2002). These determinations are driven by what is perceived to be the most efficient use of temporal resources (Bluedorn \& Jaussi, 2008; Eisenhardt, 1989), not necessarily the fastest route to completing the work. These determinations can be made very quickly (i.e. within minutes) in a team's experience together (Gersick, 1988; Zijlstra, Waller, \& Phillips, 2012).

Under stable conditions, team functioning will be unaffected by endogenous or exogenous changes, such as changes to deadlines (Waller et al., 2002). Research leads us to expect that under stable conditions the pace established by teams at the outset of their work will persist along a relatively continuous trajectory. Teams form routines early in their experience that are persistent and resistant to change (Gersick \& Hackman, 1990; Feldman, 1984). Similarly, Gersick (1988) showed that team work activities could be characterized as states of inertial equilibrium that begin to stabilize as soon as a team comes together. This is consistent with Harrison and colleagues (2003) findings that the pace teams set at the outset of their work together tends to persist unchanged as their work progresses. Considering that pace 
determinations are a function of teams' shared knowledge structures (Orlikowski \& Yates, 2002), research showing that such structures persist even in the face of member turnover (Lewis et al., 2007) further supports the premise that shared temporal structures are persistent as well.

While we argue that under stable conditions patterns of team pacing should be continuous and persistent, this does not necessarily mean that they will be static. Several studies have shown that teams show slight, steady increases in attention to time as they get closer to a deadline (e.g., Chang, et al.,, 2003; Karau \& Kelly, 1992; Lim \& Murnighan, 1994; Okhuysen, 2001; Parks \& Cowlin, 1996; Waller et al., 2002). The rationale is that teams will pay greater attention to the allocation of a resource when there is less of it available. While these studies do not consider pace as the rate of work per se, they do support our premise that teams will exhibit a pattern of pace that slightly increases as they approach a deadline. This pattern is determined at the outset of team activity based on perceived task requirements and resources, and that even if they are interrupted by periodic transitions, will persist as teams make adaptive changes to pacing (Gersick, 1988).

When a team's task context is changed, such as by the imposition of a hastened deadline or an increase in workload, it is likely to trigger a transition in team activities (Okhuysen \& Eisenhardt, 2002). While Gersick talks about transitions as opportunities for a team to make "paradigmatic shifts in their approaches to their work" (1988, pp. 32), transitions also can be conceptualized as opportunities for teams to make similar magnitude changes in the pace of their work. Subsequent empirical research supports this finding, showing how exogenous changes, such as hastened deadlines, trigger transitions where teams actively reconsider their progress toward task completion and their remaining resources, namely time, and adjust their behavior 
(e.g., work pace) as necessary to complete the task (Okhuysen \& Waller, 2002; Okhuysen, 2001;

Waller et al., 2002).

\section{Study 1}

In Study 1, we examine the role of pace deviating from the stable condition and team creative processes and team creative performance when a task context change occurs in the form of a hastening team deadline. We define deviating patterns of pace as the average deviation of team pace from the pace that would take place under stable conditions where no exogenous change is introduced. Teams that are not faced with unexpected exogenous changes in the task context keep working under stable conditions with their pacing slightly increasing as they approach the deadline. When the team deadline is hastened, teams will evaluate the appropriateness of their work pace prior to the transition in terms of how well they are suited to help them accomplish their new goal in light of the change. As a result, teams are likely to determine that their earlier pace of work is not appropriate given the new deadline, being too slow to accomplish what they need to do in the time remaining. The exogenous change of a hastened deadline will cause teams to engage in a transition, following which they will likely choose a faster pace that they deem more appropriate to meet the new deadline. This new pace is likely to be even faster than what the team would have chosen had they been aware of this hastened deadline from the start, in an effort to compensate for the inadequacy of their work pace prior to the change.

We argue that the timing of the unexpected change in the task context can result in different levels of deviating patterns of team pace depending on when this exogenous change is introduced. Specifically, we argue that when the hastened deadline is introduced later in the team's overall work process, it will result in a more deviating pattern of pacing than when it is 
introduced earlier in the team's work process. This would occur because when the hastened deadline is introduced later in the team's work process this leaves the team with less time remaining in which to reallocate necessary performance activities. Therefore, this will cause teams to have to adapt their work pace to a more extreme level than when the hastened deadline is introduced earlier in their work process. So while we expect that all teams with a hastened deadline will have deviating patterns of pacing, those receiving the hastened deadline later in their work process will have even more extreme deviating patterns of pacing as opposed to those teams receiving it earlier in their work process. The full pattern of team work pace will be significantly different between teams who have a stable deadline and those where the deadline has been hastened. Looking at the full pattern of team pacing implicates the choices made by teams before the change as well as those after the change. Those patterns of pace that result from teams operating under stable task contexts we refer to as 'continuous,' whereas those patterns that result from teams being forced to cope with unexpected changes in task context we refer to as 'deviating.' Accordingly, we hypothesize the following:

H1. Teams receiving the hastened deadline later in their work process will have more deviating patterns of pacing as opposed to those teams receiving it earlier in their work process.

Exogenous changes to task context will not only create patterns that are deviating in pace, but these deviations will in turn undermine team creative performance. Creative tasks are a representative example of how teams work together on complex, non-linear tasks. These tasks offer no temporal milestones or defined task phases inherent in the task structure by which teams can mark their progress towards their goal or assign time to various activities. When a team increases their work pace in response to a change, it can adversely affect the team's ability to stay 
effectively engaged in the creative task. A significant increase in the pace of creative work also may cause teams to become overly focused on individual ideas, potentially leading to what could be termed colloquially as losing the forest from the trees. Finally, and perhaps most importantly, the disparity in pace of task work before and after an unexpected deadline change will cause teams to commit more cognitive resources to their awareness and monitoring of temporal resources (Blount \& Janicik, 2001). Just as teams pay more attention to time as they get closer to a deadline (Waller et al., 2002), a change to task context will have a similar effect.

Again, we further argue that when the nature of the change to task context interferes directly with a team's timing of work activities, changes experienced later in a team's work process will have a differentially worse impact on team creative performance than when the same changes are experienced earlier in their work process. It is particularly important to note that we expect the above arguments to hold true independent of any experienced time pressure that might result from this exogenous change. Time pressure refers to a team's perception, whether associated with a change or not, that there is not enough time allotted to complete the assigned task. High levels of time pressure have been shown to have adverse implications for team creative processes and performance (Baer \& Oldham, 2006). Deviations in team pace and the resultant negative implications for team creative performance can be expected even in contexts where the team still perceives that it has adequate time to complete the task. Therefore: H2. Changes to task context that hasten a team's deadline will be detrimental to team creative performance, with the lowest creative performance occurring when the deadline change is introduced later in their team work process.

As we have discussed, an exogenous change is likely to initiate a transition in team pacing, during which they will 1) evaluate the appropriateness of their earlier work pace and 2) 
make adjustments as necessary. First, a hastened deadline is likely to cause a team to evaluate its prior work pace as inadequate in light of the new task context. The choice a team makes at the outset of its work regarding the appropriate level or pace of work is based on an initial set of expectations regarding task requirements and resources. More importantly, a team is likely to persist along this course until a change in the task context is experienced. The critical impact to creative processes occurs after an exogenous change is experienced by a team. We argue that team creative processes will mediate the relationship between pace deviation and creative performance. Engagement in creative processes involves multiple activities (Amabile, 1983; Shalley \& Perry-Smith, 2008; Zhang \& Bartol, 2010), such as problem identification, broad search of the environment to access different knowledge sources, the generation of multiple ideas, the evaluation of different options, and the refining of ideas including combining ideas until one idea is ultimately selected for implementation (Amabile, 1983). Engaging in creative processes is the means by which teams convert collective cognitive resources into creative outputs (Zhang \& Bartol, 2010). The perception that the team needs to speed up its work pace can dampen the free flow of ideas, causing the team to become prematurely 'locked' into a particular stage of creative processes or on a premature idea, failing to pursue more promising avenues and attaining more novel insights. In other words, having deviating patterns of pacing can hinder creative processes as members simply feel pressured to settle on sub-optimal creative solutions in order to keep moving forward to complete the task within the time allotted.

Hence, we hypothesize that task pacing deviation will have a negative impact on team creative processes, that will in turn weaken team creative performance.

\section{H3. Team creative processes will mediate the negative effects of pace deviation on team} creative performance. 


\section{Methods}

We test the effect of unanticipated changes to task context by imposing a hastened deadline on teams performing a creative task. Our design is a hybrid of an experimental design and non-experimental lab study (LePine, 2003). Participants were randomly assigned to teams of three, and the teams were randomly assigned to one of four conditions. There was a control condition and three manipulation conditions. The principal manipulation was "no change to deadline' versus 'change to deadline', with three conditions for the timing of when the change to deadline is introduced. We used three time periods in order to evaluate the extent to which the timing of the exogenous change influences our effects. The manipulation was based on the introduction of a hastened deadline constraint, going from being told originally that they had 40 minutes to work on a task to only having 20 minutes to complete the task. Specifically, the deadline constraint was introduced at 5, 10, or 15 minutes into the teams allotted task time. The control group was told from the beginning that they had 20 minutes to work on the task, with no change in deadline. Pretesting indicated that an appropriate amount of time to complete this task was 20 minutes, and all teams were able to complete the task by the end of this 20 -minute period.

A complex heuristic task was developed for this study that required teams to come up with a five year transition plan for a restaurant in which the founder and chef was retiring, while the restaurant and associated businesses (e.g., cooking school, cookbooks) were expected to continue. The task was based on an actual head chef, Ferran Adria, and his 'el Bulli' restaurant, world renowned for innovative cuisine, presentation, and the overall dining experience. Team members were asked to independently read a passage providing background on the history of the business, the founder, their diverse business holdings, and what the task would involve. Specifically, they were told that their team's task was to help determine the future of the el Bulli 
Enterprises following Adria's retirement in six months. Teams were told to develop a five-year plan detailing what el Bulli Enterprises should do next to continue its success in Adria's absence. Teams were told that their proposal would be evaluated based on its creativity and comprehensiveness, and that those teams whose solution was rated by judges to be in the top $20 \%$ of teams participating would receive $\$ 75$ cash ( $\$ 25$ per team member). This was done to motivate members to fully participate in the teams' work process and contribute to their final performance. The task was pretested to ensure that it was engaging and that performance would generate requisite variance.

This study utilized 216 participants for a total of 72 teams. All participants were undergraduate students in a southeastern college in the United States, participating for course credit. Participants were evenly split between males and females (49\% vs. 51\%) averaging 20.5 years in age, with a range of 18 to 39 . The majority of these participants were majoring in Business Administration (91\%), and the rest were distributed across various majors. There were 14 teams in the control condition, 18 in the hastening deadline at 5 minute condition, and 20 in each of the hastening deadline at 10 and 15 minutes conditions.

\section{Procedures.}

When participants arrived at the behavioral laboratory for an hour-long study, they were seated in a large room and asked to read and sign their informed consent form if they were willing to participate in this study. The experimenter then gave standard instructions to the whole group of participants about general procedures for the study. They were asked to individually read the task so that each participant had time to think about the task. Then the experimenter broke participants into teams of three individuals and escorted them to private rooms for the rest of the session. Further instructions were given to each team regarding how the team task was 
specified, and a video-camera was turned on in each room to tape teams' discussions. A timer also was in the room so that they could keep track of time. At the appropriate time for their condition, the experimenter reentered the room and gave the manipulation of a hastened deadline constraint. After a total task time of 20 minutes, each team turned in their written 5-year plans. They were then requested to individually fill out a final questionnaire that contained questions about whether their team experienced time pressure and demographics, and then they were debriefed.

To induce the manipulation of hastened deadlines, all three manipulation conditions were originally told that they would have 40 minutes for the task, then at five (or ten or fifteen) minutes into the task the experimenter informed teams that "the owners are becoming anxious about what their next step will be, so they have asked for the teams to speed-up their timetable for delivering the 5 year business plan. As such, the total time allotted for this task is now 20 minutes, which means you have five (or ten or fifteen) minutes left to work." Teams in the control condition had 20 minutes for working on the task. Therefore, all teams in each condition had the same length of time to complete the task.

\section{Measures.}

Creative Performance. Using the consensual assessment technique (Amabile, 1983), three graduate student raters who were trained specifically in this type of evaluation and who were blind to the experimental conditions independently coded each team's output with respect to rating the following three items: overall creativity, novelty, and usefulness. Each of these items was explained to the raters, and any questions they had were answered. They rated these three items on a 1-7 point scale with $1=$ not at all creative/novel/useful to $7=$ extremely creative/novel/useful. Once the ratings were completed, inter-rater agreements (i.e., rwg scores) 
were calculated to make sure that there was sufficient agreement among the three raters to merit averaging their ratings into one composite score. The rwg score for the 3-item scale of creativity of the 5-year plan was .92 , (Cronbach's alpha=.89). Therefore, ratings of the three judges for the three items were aggregated to form a measure of team creative performance.

Process Factors. We focused on two process factors: 1) the pace of teams' work activities and 2) creative processes before and after the introduction of the change. These process factors were evaluated by two independent coders who were blind to the experimental conditions, who watched each team's videotape. Each of these process factors was defined for and discussed with the two coders so that there would be greater understanding of the underlying constructs and thereby greater consistency in their coding. The inter-rater agreements (i.e., rwg) for these were high; therefore the two coders' ratings of these process factors were combined to form a rating of each process factor.

To rate the pace of team work activities, coders were instructed to evaluate the extent to which team activities were focused, engaged and purposeful toward completing the assigned task successfully, including non-verbal cues and any engagement in non-performance related activities. This approach was chosen over more alternative metrics of pace like counts of team members statements (Gersick, 1989), because such measures fail to incorporate meaningful nonverbal cues and other interactions that are indicative of pace, which are especially relevant when evaluating team work activities on abstract, non-linear tasks like the one employed in this study. The pace of team work was rated by coders by evaluating how effectively the teams closed off one activity and moved the team's focus to the next step. The coders independently evaluated team pacing at every 5 minute interval during the 20 minutes that the team was working on the task, yielding four sets of pacing scores for each team. The rwg between the judges for the total 
20 minute period averaged .87 with agreement for pacing, with each 5 -minute period being .85 , $.87, .88$, and .87 respectively. Deviation in patterns of pace was captured by comparing the sequence of pace measure for each team to the sequence of pace measure derived from the stable (i.e. no hastening deadline) control condition. Teams in the control condition served as a meaningful point of comparison for evaluating how teams that were subjected to change were affected in terms of pacing since they received no change. This is preferable to comparing team pace to a static mean, because research indicates that even under stable conditions pace will naturally increase slightly over time. Our approach allows an archetypal pattern of team pacing to emerge naturally in the stable control condition. We calculated deviating patterns of team pace by comparing the score for each team for each 5-minute time period in a team's sequence against the mean for the same time period in the control condition. The absolute values of these differences were averaged to yield a single metric reflecting the extent to which each team in the manipulation conditions deviated from the pattern of pacing exhibited by the aggregate of teams in the control condition.

To rate team creative processes, two coders who were blind to the experimental conditions independently viewed the videotapes and coded for creative processes before and after the change for six behaviors related to creative processes (Amabile, 1983; Shalley, Zhou, \& Oldham, 2004): (1) The team members tried hard to be creative in their thinking, (2) The team members built on other members' ideas (e.g., added or recombined ideas), (3) Team members generated a number of ideas, (4) Team members generated ideas that were highly novel/original, (5)Team members constructively reacted to ideas (e.g., positive, critical), and (6) There was a lot of divergent thinking. The rwg between the two raters for creative processes before the hastening deadline was .92 , and after was $.85(\alpha=.91$ and .93 , respectively). 
Experienced Time Pressure. In order to ensure that all teams experienced the same overall sense of experienced time pressure across the 20-minute task time, we used a six-item measure to capture participants' perceptions at the end of the study with very good overall agreement $(\alpha=86)$. The items were: 1) I felt we had enough time to complete the task (reverse coded); 2) I think I had plenty of time to generate ideas for the task (reverse coded); 3) I felt pressure to complete the task in the time allotted; 4) I felt that the amount of time was an issue in how we worked on the task; 5) I focused on working quickly; and, 6) I felt intense during the study.

\section{Analyses and Results}

In order to confirm that our manipulation affected the hastening of the deadline but not the amount of time pressure felt by the teams, we ran a one-way ANOVA to see if teams in all the conditions experienced comparable amounts of time pressure over the course of working on the task. As expected, time pressure experienced by the teams was not significantly different across conditions $\left(F(3,68)=1.44, \mathrm{p}>.05, \eta^{2}=.06\right)$.

The correlations among variables were as expected. There was a positive correlation between team creative performance $($ mean $=4.54 ; S D=.71)$ and team creative processes $($ mean=4.17, $S D=1.01)(r=.24, p<.10)$. Deviating patterns of pace $($ Mean=2.53; $S D=1.82)$ had a negligible correlation with team creative performance $(r=.06, p>.05)$, but was negatively correlated with team creative processes $(r=-.38, p<.01)$. Means and standard deviations of each condition can be seen in Table 1.

Insert Table 1 about here 
To test Hypothesis 1, we conducted a one-way ANOVA to determine whether changes introduced later in the teams' work process have a differentially worse impact on deviating patterns of pace. We did not find any significant difference on deviating patterns of pacing among the four conditions $\left(F(3,68)=.67 \mathrm{p}>.05, \eta^{2}=.03\right)$, so we failed to find support for Hypothesis 1 . However, as suggested, in looking at the pattern of the means, teams that received the deadline change earlier in the work process had the least deviating patterns of pace, with the 5 minute condition having a mean of .53 and the 10 minute condition having a mean of .64, compared to the later condition that had the highest deviating patterns of pace with a mean of .71. Figure 1 shows a comparison between the teams that did not receive any task context change (i.e. the control condition) versus those that received the hastening deadline change later during the team process (i.e., at 15 minutes into the task). As can be seen in this figure while the control condition has a steadier overall pattern, the teams that received an exogenous task context change of a hastening team deadline later in the team process experience a more dramatic pattern of pacing throughout their work.

Insert Figure 1 about here

Hypothesis 2 was tested with a one-way ANOVA on team creative performance. The results showed significant differences among the four conditions $(F(3,68)=4.43, \mathrm{p}<.001$, $\eta^{2}=.16$ ). Table 1 presents the means and standard deviations for each condition. The Tukey posthoc tests indicated that the teams that experienced the hastening deadline change later in their work process (mean=4.08) had significantly lower creative performance compared to the control condition (mean $=4.78, \mathrm{p}<.05$ ), and compared to teams that received the exogenous change earlier in their work process at 5 minutes into the task (mean=4.69, $\mathrm{p}<.05)$ and 10 minutes into 
the task $($ mean $=4.69, \mathrm{p}<.05)$. There were no other significant differences among the conditions. Therefore, Hypothesis 2 was fully supported.

We also tested the impact of the timing of the exogenous change on differences between the manipulation conditions using team creative processes before and after the experienced deadline change. As expected, creative processes before the introduction of the hastening deadline was not significantly different among the three manipulation conditions $(F(2,55)=.18$, $\left.\mathrm{p}>.05, \eta^{2}=.01\right)$. However, creative processes after the introduction of the change was significantly different among the three manipulation conditions $\left(F(2,55) 5.24, \mathrm{p}<.01, \eta^{2}=.16\right)$. According to the post-hoc analysis, those who received the hastening deadline change earlier in their work process at 5 minutes into the task had higher creative processes after the change $($ mean $=4.50)$ than those who received the change later at 15 minutes into their work process $($ mean $=3.64, \mathrm{p}<.01)$. The creative processes of those receiving the hastening deadline in the 10 minute condition had a mean of 4.34 , which was somewhat higher than the creative processes of the later condition $(p=.055)$ but not significantly higher. These results indicated that when the hastening deadline changes occurred later in their workflow it was most detrimental for creative processes of the team as compared to when the hastening deadline was introduced earlier in their workflow.

Hypothesis 3 was tested using Preacher and colleagues (2007) mediation analysis with 5000 bootstrapping samples. While testing the mediation effect of team creative processes after the introduction of the change between deviating patterns of pacing and team creative performance, we controlled for the effect of team creative processes before the change and time pressure in order to avoid any alternative explanations. Creative processes before the change $(\beta=.04, S E=.13, p>.05)$ and time pressure $(\beta=.02, S E=.12, p>.05)$ did not have significant 
effects on teams' creative performance. Deviating patterns of pacing negatively influenced team creative processes after the change $(\beta=-.58, \mathrm{SE}=.26, \mathrm{p}<.05)$. There was also a significant and positive relationship between team creative processes after the change and team creative performance $(\beta=.29, \mathrm{SE}=.11, \mathrm{p}<.05)$. Therefore, there was a negative indirect relationship between deviating patterns of pace and team creative performance, acting through team creative processes, with a point estimate of -.17 . The bias corrected confidence interval for this relationship ranges between -.47 and -.02. Therefore, Hypothesis 3 was supported. The direct $\operatorname{effect}(\beta=.40, \mathrm{SE}=.22, \mathrm{p}>.05)$ and total $\operatorname{effect}(\beta=.22, \mathrm{SE}=.22 \mathrm{p}>.05)$ of deviating patterns of pace on team creative performance were not significant. Since current approaches to mediation analysis do not require demonstrating a direct effect between the independent and dependent variables (Hayes, 2013), given the significant results showing that our independent variable predicts our mediation and our mediator predicts our dependent variable, we can conclude that this hypothesis was supported (Hayes, 2009).

\section{Discussion of Study 1}

In Study 1, we tested the effect of a task context change in the form of changes to team resources by introducing a hastened deadline on team creative processes and performance. We did not find significant differences between conditions when we compared the overall differential pacing of each condition to the stable patterns of pacing (i.e., deviating patterns of pacing versus continuous patterns of pacing). However, we found that as suggested teams that received the deadline change later in the team work process was most detrimental for team creativity compared to the teams that had not received a deadline change, or received the change earlier or at the midpoint of their work. Receiving a deadline change later in the work process also had detrimental effects on teams' creative processes. Specifically, teams that received the 
change later had significantly lower creativity than the ones who received the change earlier. We also found that deviations in team patterns of work pace negatively influenced team creative performance via team creative processes after the change. Interestingly, however, we found no direct relationship between deviating patterns of pace and team creative performance. This may simply be a function of inadequate power given the model we tested and the actual effect sizes in our study. Finally, it is important to note that the time pressure experienced by teams whose deadlines were constrained does not explain our results. This alternative explanation was tested with no significant results.

An unexpected finding was that the time pacing of the control condition teams actually decreased during the second half of their allotted time, a finding that runs counter to prior findings that teams will slightly increase their pace as they approach a deadline (Waller et al, 2002). This result can perhaps be interpreted as a function of our task actually requiring less time than we had expected based on our pretest. Specifically, it may be that the teams did not need the full 20 minutes to complete the task from the beginning. Teams in the control condition might have reached a point where they expected to complete the task earlier than the 20 minutes allotted. Another potential explanation may be the inclusion of a monetary incentive in Study 1 that we did not include in our pretest, and this may have motivated teams to complete the task in less time than expected.

\section{Study 2}

While there are a number of prior studies on changes to team resources, most notably in terms of changes to team membership (Lewis et al., 2007) and deadlines (Ballard et al., 2008), there is far less work on the effects of changes to team workloads. Our purpose in Study 2 was to replicate the effects of Study 1 with a different category of change to task context. Specifically, 
we manipulated the level of workload, or a type of change that affects what is expected of the team to achieve positive task performance, with no change in the team's temporal resources. As such, we focused on having no change in the team deadline, since the effects of the exogenous change were not associated with proximity to the deadline. By means of this replication, we seek to confirm that the effects we found in Study 1 are not simply the result of teams being more attenuated to considerations of remaining time when changes to deadlines are involved, which can serve to make pace choices more salient. We look at the effect of exogenous changes for the two main forms of task context changes (i.e., resources and work expectation changes) to be more complete in our examination of exogenous changes. Attempting to replicate our findings in situations involving additions to workload also promises to yield greater insight into the effects of unexpected changes to task contexts on creative performance. As we noted in Study 1, the finding for a difference in creative performance only for the later condition might suggest that unexpected exogenous changes only undermined team performance when they occur closer to the deadline. This finding may have been the result of the conservative design employed in Study 1, where only the deadline was changed and the workload requirement remained stable. It may be that unexpected changes to workload are more disruptive to team pacing, creative processes, and performances, given that such changes require teams to not only consider how to reallocate their efforts, but also to rebalance their cognitive attention between the old and new task requirements. Therefore, a study of unexpected additions to workload may produce a clearer picture of the effects of such task context changes on team creative performance.

A secondary purpose in designing Study 2 was to consider whether we could replicate our original results in the context of when change is experienced at a stable temporal midpoint in the teams' workflow. Specifically, prior research (e.g., Gersick, 1989) has indicated that the 
midpoint is an important temporal marker for performing work, similar to when you are getting closer to a deadline. In Study 1, we didn't have a true midpoint, since teams in the hastening conditions were originally told that they had 40 minutes to work on the task and then this was changed to 20 minutes. Our focus on workload changes in Study 2 does not interfere with the temporal resources available to the team, nor does it alter the temporal midpoint. Therefore, finding support for the disruptive effects of exogenous changes on pacing, creative processes, and creative performance effects when such a change is experienced at the midpoint can improve the robustness of our findings from Study 1. By leaving the temporal midpoint intact, the current study promises to inform us as to whether the negative effect of exogenous change is limited to those experienced only later in the work process or if change experienced at the midpoint of a team's workflow also can be detrimental.

\section{Workload changes to task context}

In contrast to the body of research on team deadlines, there is far less research on how teams respond to an exogenous change in their task requirements or workload (Bowers, Braun, \& Morgan, 1997). What work there is takes a very similar perspective to studies of changes in deadlines, focusing on the qualities or strategies employed by teams that allow them to successfully adapt to the change in workload. For instance, Porter, Webb, and Gogus (2010) examined the extent to which team learning and performance orientations have independent as well as interactive (i.e., interfering) effects on teams' ability to adapt to sudden and dramatic changes in workload.

There is a little more research on how teams will respond to changes experienced concurrent with a temporal midpoint transition. For example, Woolley (2009) studied whether a process or outcome focus in teams would better help them to accommodate changes in task 
context or membership experienced at the temporal midpoint. Her results showed that outcome focused teams were better able to adapt and ultimately perform in the face of exogenous changes. Knight (2013) showed how different team moods experienced at the midpoint affected how teams were able to engage in effective midpoint transitions. One of the benefits of our Study 2 is that we can consider whether the midpoint, in addition to changes later in their work process, represents a unique point of vulnerability in teams' experience of exogenous change.

As we argued in Study 1, unexpected changes will disrupt the normal flow of a team's work. At the inception of work, teams will allocate time to various work activities based on what is required by the task and how much time is allotted. These initial determinations continue to guide how and when teams need to adjust their activities to accomplish their task within the allotted time (Waller et al., 2002). This is especially true for teams engaged in creative tasks, given that the non-linear and iterative nature of creative processes means teams cannot count on using the task itself to mark progress (Marks et al., 2001). Therefore, changes that increase creative task requirements will require teams to think actively about what remains to be done to complete what they were originally working on, and what is required to complete the additional workload. The cumulative effects of exogenous changes will result in deviations in the patterns of team pacing in the same manner as described in Study 1.

In addressing the role of timing as a determinant of the impact of changes in task requirements on team functioning, we also consider the midpoint as a particularly relevant point in a team's work process, in addition to receiving changes in task requirements later in their work process. The midpoint logically bifurcates a team's efforts based on the time allotted for the task. Gersick (1989) explains that the groups she studied "paid special attention to time at the midpoint of their time spans, made abrupt shifts in the focus of their work activities, and 
depended on midpoint agreements to provide a basis for work in the second half of their time" (p. 305). Research also has shown that experiencing midpoint transitions in team work is positively linked to teams' use of effective task pacing strategies (Okhuysen \& Waller, 2002). Effective midpoint transitions are especially important to the pacing of work in ambiguous tasks like team creative work. Creative teams that experience exogenous changes concurrent with the midpoint transition or later will be less likely to efficiently manage the teams' efforts to reach the conclusion of the task (Okhuysen \& Waller, 2002). When the exogenous change does not alter a recognizable temporal midpoint, we argue that this midpoint may actually function as a unique point of vulnerability in addition to changes experienced later in their workflow. Specifically, changes that occur at the midpoint will equate to more deviation in how teams pace their performance activities, which predicts weaker creative processes and performance.

We argue that teams experiencing change at the midpoint or later in their work process will have a harder time navigating changes in task requirements. As a result, at both of these points teams are more likely to be concerned about the lack of progress made earlier in their work process, especially in light of this added workload, and more likely to increase their task intensity following the change to compensate for this. Added together, the slower pace before the change and the reactive increase in pace following the change will produce a deviating pattern of team pacing than teams receiving the exogenous change in workload earlier in their work process.

H4. Teams receiving the increased workload at the midpoint or later in their work process will have more deviating patterns of pacing as opposed to those teams receiving it earlier in their work process. 
The demands of addressing the new task requirements and making temporal allocations following a change will distract team members from the task of adjusting and re-establishing effective team processes following the change, and teams will commit less effort to the task of transitioning their team processes to the remaining period of work, undermining creative performance. As a result, teams will not make the best use of the time available to them, undercutting their application of collective cognitive resources and ultimately their creative performance (Zhang \& Bartol, 2010). The midpoint is also a logical point at which teams will reconsider their approach to their work, adjusting and re-establishing work processes for the time remaining for the task (Gersick, 1994). Failure to adjust team processes for the remainder of the time allotted for the task may result in a team spending too much time exploring new ideas and spending less time on choosing and refining creative ideas, undermining their eventual creative performance.

We further argue that a change in task requirements experienced at the midpoint or later in a team's work process is more likely to cause the team to react adversely than when changes are experienced earlier in their work process. Changes at the midpoint are more likely to interfere with a team's transition efforts (Gersick, 1989), and ultimately hurting their creative performance. At the midpoint, team members' attention will be more focused on team progress, increasing the likelihood that changes will be perceived as adversely impacting that progress.

H5. Changes to task context that increase a team's workload will be detrimental to team creative performance, with the lowest creative performance occurring when the workload change is introduced at the midpoint or later in their team work process.

We again consider the extent to which the effects on creative processes will mediate the adverse impact realized by the teams' patterns of pacing. The deviating patterns of task pacing 
that result from an exogenous change will adversely affect teams' ability to stay effectively involved in their creative processes (Chun \& Kruglanski, 2006; Huey \& Wickens, 1993; Salvucci \& Taatgen, 2008), undermining team creative performance.

H6. Team creative processes will mediate the negative effects of deviating patters of pacing on creative performance.

\section{Methods}

A hybrid experimental 1 X 4 design similar to that used in Study 1 was employed. Participants were randomly assigned to teams of three, and the teams were randomly assigned to one of four conditions, including a control condition. In the three manipulation conditions, an addition to the workload of each team was introduced at either 5 minutes, 10 minutes, or 15 minutes into the 20 minutes allotted for their work. All teams started with the same complex heuristic task as in Study 1, and they were instructed that they would have to come up with a five-year plan for a restaurant in 20 minutes. The manipulation of workload increase was accomplished by the experimenter returning to the room while the team was working and informing them that the restaurant owners would like them to address an additional directive. Specifically, the teams were asked to propose a comprehensive public relations plan to support the new restaurant strategy they were proposing. The control group condition received the full set of directives at the beginning of their work.

The same procedures were used here as in Study 1. Teams were told their proposals would be evaluated for creativity and comprehensiveness, and that those teams whose solution was rated by judges to be in the top $20 \%$ of teams participating would receive $\$ 75$ cash ( $\$ 25$ per team member). Almost all teams completed the entire task (i.e., 5 year business plan plus the 
public relations plan) in 20 minutes. Only two teams finished the five year business task but did not completely finish the public relations plan in the 20 minutes.

In total, 213 participants were randomly assigned to three person teams for a total of 71 teams. Participants were students at a U.S. southeastern university, part of a standing subject pool required to participate in research for course credit. Forty four percent of the participants were female, with an average age of 20.6, and a range of 18 to 35 . The majority of these participants were majoring in Business Administration (94\%), with the rest of participants across various majors. There were 15 teams in the control condition, 19 in the 5 and 10 minute conditions, and 18 in the 15 minute condition.

\section{Measures.}

Creative Performance. Using the same consensual assessment technique (Amabile, 1983) employed in Study 1, three graduate student raters who were trained specifically in this type of evaluation and who were blind to the experimental conditions independently coded each team's output with respect to rating the following three items on a 1-7 point scale: overall creativity, novelty, and usefulness. The rwg score for their output was .92 (Cronbach alpha=.94). Therefore, the judges' ratings were aggregated, and the three items were averaged into a team creative performance score.

Process Factors. As in Study 1, we focused on two process factors: 1) team creative processes before and after the introduction of the change and 2) team task pace. These process factors were evaluated by two independent coders who were blind to the experimental conditions. The rwg between the two raters for creative processes was .82 for before the change, and .85 for after the change ( $\alpha=.92$ and .95 , respectively). The rwg between the judges on team task pace for the total 20 minute period averaged .80 agreement for task pace, and for each 5- 
minute time period they were $.80, .80, .78$, and .82 respectively. Again, deviating patterns of task pacing was calculated by comparing the score for each team for each time period against the mean for the same time period in the control condition, with the absolute values of these differences being averaged to yield a single metric reflecting the extent to which each team in the manipulation conditions differed from the pattern of task pacing exhibited by the aggregate of teams in the control condition.

Experienced Time Pressure. In order to ensure that all teams experienced the same overall sense of experienced time pressure across the 20 -minute task time, we used the same time pressure measure that was used in Study $1(\alpha=.82)$.

\section{Analyses and Results}

Following the same steps as Study 1, we ran a one-way ANOVA to see if teams in all the conditions experienced comparable amounts of time pressure over the course of working on the task. As expected, time pressure experienced by the teams was not significantly different from each other across conditions $\left(F\left(3,68=.44, p>.05, \eta^{2}=.04\right)\right.$.

Study 2 results showed that the correlations among variables were consistent with our hypotheses. Specifically, team creative performance (mean $=4.08 ; S D=.88)$ and team creative processes $($ mean $=4.37, S D=.88)$ were positively correlated $(r=.51, p<.01)$. Deviating patterns of pacing $($ Mean $=.89 ; S D=.45)$ was negatively correlated with team creative performance $(r=-.20$, $p>.05)$ and team creative processes $(r=-.36, p<.01)$. The means and standard deviations of each condition can be seen in Table 2 .

Insert Table 2 about here 
To test Hypothesis 4 and see the effect of the timing of the workload change on deviating patterns of pacing, we ran a one-way ANOVA. The results showed significant differences among the four conditions $\left(F(3,68)=3.48, \mathrm{p}<.05, \eta^{2}=.14\right)$. According to the post-hoc analysis, the teams that received a task context change in their workload at an earlier point of time had significantly lower deviating patterns of pacing (mean $=.17, \mathrm{p}<.05)$ than the midpoint condition $($ mean=.27) and the later condition (mean=.24), with no significant differences between these two conditions. These results provided evidence that task context changes at the midpoint and later in their work process lead to more deviating patterns of pacing, providing partial support for H4. Furthermore, teams that received the additional workload from the inception of their work together (i.e. control condition) exhibited slightly increasing patterns of pacing, while teams that received the additional workload right at the midpoint (i.e. 10 minutes condition) had deviating patterns of team pacing, characterized by a decrease in pacing after the change followed by a similar increase in pacing (see Figure 2). This decrease may be due to the teams' shifting their attention to the midpoint transition (Gersick, 1989). However, after the five minute period following the change, when there was only a little more time to complete the task, the teams again picked up their pace with a sizeable increase. A similar pattern can be seen in the 15 minute condition in terms of the drop in pacing following the change (See Figure 3); however a corresponding increase in pacing following that is not observed, perhaps because of a restricted range in time.

Insert Figures 2 and 3 about here

A one-way ANOVA for team creative performance showed significant differences among the four conditions $\left(F(3,68)=6.88, \mathrm{p}<.001, \eta^{2}=.23\right)$. Specifically, the Tukey post-hoc 
tests indicated that teams that received the change at the midpoint (mean $=3.60, \mathrm{p}<.01$ ) or later during their work process (mean $=3.80, \mathrm{p}<.01)$ were significantly less creative than the control condition that received the full workload at the very beginning of the study (mean=4.70). Teams that received the additional workload at the midpoint also had significantly lower creativity than the earlier condition (mean=4.32, $\mathrm{p}<.05$ ). Hence, we found partial support for H5. We ran a further analysis on team creative processes before and after the task change by conducting a oneway ANOVA. We found that as expected, team creative processes before the workload change was not significantly different across conditions $\left(F(2,53)=.46, p>.05, \eta^{2}=.03\right)$, yet team creative processes that occurred after the addition of workload was significantly different between the three manipulation conditions $\left(F(2,53)=4.87, \mathrm{p}<.05, \eta^{2}=.16\right)$. Specifically, the post-hoc analysis indicated that teams that received the change earlier in their work process (mean=4.84) had significantly higher creative processes than those who received the change at the midpoint $($ mean $=4.07, \mathrm{p}<.05)$ and those that received the change later in their work process $(\mathrm{mean}=4.18$, $\mathrm{p}<.05$ ). These results support $\mathrm{H} 5$, in that the task context changes have the worse impact on teams that were told of the change at the midpoint or later in their work process, with there being no significant difference between those told of the workload change at the midpoint versus when it occurred later in their work process.

Hypothesis 6 was tested using Preacher, Rucker, \& Hayes (2007) mediation analysis with 5000 bootstrapping samples. The partial effect of the first control variable, creative process before the change, was significant for team creative performance $(\beta=.23, \mathrm{SE}=.11, \mathrm{p}<.05)$, while the effect of the second control variable, time pressure, was not significant $(\beta=-.17, \mathrm{SE}=.11$, $\mathrm{P}>$.05). Deviating patterns of pacing negatively influenced team creative processes after the change was introduced $(\beta=-2.53, \mathrm{SE}=.79, \mathrm{p}<.01)$. There was also a significant and positive 
relationship between team creative processes after the change and creative performance $(\beta=.29$, $\mathrm{SE}=.15, \mathrm{p}<.05)$. Therefore, there was a negative indirect relationship between the deviant pattern of task pacing and team creativity through team creative processes, with a point estimate of -.75. The bias corrected confidence interval for this relationship ranges between -1.97 and -.04 , supporting this hypothesis. The direct effect $(\beta=-.42, \mathrm{SE}=.92, \mathrm{p}>.05)$ and total effect $(\beta=-1.17$, $\mathrm{SE}=.86, \mathrm{p}>.05)$ of deviating patterns of task pace on team creative performance were not significant. Since we found significant results showing that our independent variable predicts our mediation, and our mediator predicts our dependent variable, we can conclude that the mediation hypothesis was supported (Hayes, 2009).

\section{Discussion of Study 2}

Our results of this study showed that changes to task context that increase teams' workload result in deviating patterns of team pacing. Specifically, we found that teams receiving the additional workload at the midpoint or later in their work process had a higher deviation of pacing compared to the teams that received this change earlier in their work process. These findings add further support to our premise that deviating patterns of pacing can be detrimental to team creative processes, which in turn is negatively related to team creative performance. Moreover, changes to workload that occurred at the midpoint or later during the team work process were the most detrimental for team creative processes and creative performance. This supports our hypothesis that the temporal midpoint can be vulnerable to disruption.

Consistent with Study 1, we found that team creative processes after task context changes mediates the relationship between deviating patterns of team pacing and team creative performance. Similar to Study 1, we once again found an indirect mediation effect for creative processes, meaning that there was no direct relationship between deviating patterns of team pace 
and team creative performance. Finally, we observed different patterns of team pacing in Study 2 than those observed in Study 1. Specifically, teams in the control condition exhibited a slight increase in pacing as they approached the deadline, which is more consistent with prior perspectives (Waller et al, 2002). This also supports our explanation for the decreases in pacing observed in the control condition in Study 1, in that perhaps the task was too easily completed in the time allotted, which may have been remedied by the additions to workload in Study 2 . The patterns of pacing observed in the manipulation conditions also were different in Study 2. Specifically, in both the 10 minute and 15 minute conditions, team pacing following the introduction of the workload addition actually decreased. This suggests that the immediate effect of an addition to workload was disruptive in ways other than those hypothesized, undermining team pacing. In the 10 minute condition, we also saw that in the period following the decrease in pacing, teams exhibited a large increase in pacing, and discuss these implications further in the general discussion.

\section{General Discussion}

This research demonstrates how teams responding to an unexpected exogenous change make adaptive adjustments to their pace of work that can prove detrimental to team creative processes and performance. Specifically, we examined the role of pacing as a result of two types of task context changes (i.e. a hastening deadline change and additions to workload) on team creative processes and team creative performance. There were a number of results that were consistent across both studies. First, we found that changes to task context, either in the form of a hastening deadline change or a workload change, were detrimental to team creative performance. Second, results from both studies indicated that while creative processes after the task context change was a significant mediator of the negative relationship between deviating patterns of 
pacing and team creative performance, patterns of pace deviation actually did not have a significant direct negative effect on creative performance. This suggests that the relationship between deviating patterns of pacing and team creative performance might be more complicated than originally argued. Specifically, it might be that pace deviation has both positive and negative implications for creative performance, and that the central role of creative processes only captures these negative effects. Future research should consider that pace deviation may have positive effects on creative performance under certain conditions, and what moderators might impact whether the effects are positive or negative.

An important difference between the two studies is how the nature and timing of the change effects deviating patterns of pacing, creative processes, and creative performance. Specifically, it is true that in both studies, the introduction of an unexpected exogenous change was detrimental for task pacing, creative processes, and creative performance when it occurred later rather than earlier in the teams' work process. However, in Study 1 the hastening deadline change was only detrimental when it occurred during the last fifteen minutes of teams' work process, while in Study 2 the additional workload change was detrimental for task pacing, creative processes, and creative performance when it was introduced at the midpoint or later in the teams' process. This difference in the two studies with regard to changes being introduced at the midpoint may have occurred because in Study 1 there was no naturally occurring midpoint. That is, since the hastening deadline removed any naturally occurring midpoint, since they originally thought they had forty minutes to complete the task and then the change reduced the total task time to twenty minutes. In Study 2, the midpoint timing remained intact, allowing us to examine the impact of changes occurring at the temporal midpoint. As predicted, an unanticipated addition to workload was detrimental when it occurred at the midpoint as well as 
when it occurred later in their work process. In other words, Study 2 demonstrated that when teams have a stable temporal midpoint, exogenous changes both at the midpoint and later in their work process are detrimental to task pacing, creative processes, and creative performance. This finding is consistent with Gersick's $(1988 ; 1989)$ arguments regarding the importance of midpoint transitions, in that, the temporal midpoint can be vulnerable to disruption by exogenous change, that may interfere with an effective transition. In addition, the results showed that the timing of the deadline changes and workload changes can have different effects on deviating patterns of pacing. Specifically, we found that while the timing of the deadline change did not create significantly different patterns of pacing across conditions, introducing a workload change at the midpoint or later in their work process created significantly higher deviation than when it occurred earlier in their work process. In other words, teams can be more vulnerable to workload changes than deadline changes when they are trying to adapt to the new task requirements.

This study makes several unique contributions to the team process and creativity literatures. First, while the previous literature focused on the qualities and strategies of teams that helped them to successfully adapt to changes, we took a different perspective by focusing on how adjustments to pacing can actually undermine team processes and performance. This is an important contribution, because the dominant perspectives in the existing literature (e.g., Baer \& Oldham, 2006; Gersick \& Hackman, 1990; LePine, 2005) ignore the possibility that teams can engage in adaptive responses that could actually be detrimental to team performance. Our research contradicts these perspectives, and in today's dynamic business environment, it is critical to consider this alternative. Second, we examine the role of the timing of deadline and workload changes on team pacing, team creative processes, and team creative performance. Third, we were able to show in both Study 1 and 2 that the effects for unexpected change cannot 
be explained by differences in experienced time pressure, which could have been an alternative explanation for our findings, particularly in Study 1. Finally, these two studies contribute to helping to cement our understanding of the relationship between creative processes and creative performance in teams. There are very few studies that have considered the natural emergence of team creative processes over the course of teams working together (e.g. Zhang \& Bartol, 2010). As an addition to the existing studies, we were able to observe the causal order of changes in team creative processes subsequently effecting team creative performance in a controlled experimental setting (Fisher, 1984). Given the dynamic nature of teamwork, it is important to be able to actually examine how teams engage in their work, and how when faced with changes in task context they react and adapt. In addition, much of the creativity literature has emphasized the importance of engagement in creative processes for creative performance to occur (Shalley et al., 2004), but the majority of studies have examined creative performance or creative processes in isolation. Here we were able to show that creative processes are directly related to team creative performance, and when teams' creative processes are hindered this also affects their level of team creative performance. Furthermore, team creative processes that occurred after the teams faced an unexpected change acted as the mediation mechanism between deviating patterns of task pacing and team creative performance.

From a practical perspective, our results indicate that the timing of changes in work requirements can have practical implications for team processes and creative performance. Naturally, instead of waiting for as long as possible to tell work teams about potential changes in work expectations, it is best to announce these changes as early as possible in their work process. When this occurs, teams are able to effectively regulate their cognitive resources and adapt to these changes without negatively affecting either their teams' creative processes or creative 
performance. Managers also should be aware that when it comes to changes in workload, teams become especially vulnerable to changes at the mid-point of their work process, in addition to later changes. However, changes to a deadline at the midpoint of their work process did not result in significantly lower levels of team creative processes or team creative performance than introducing these changes earlier. What is a more important practical impact of our work is that it speaks to the caution that should be taken by teams when unexpected exogenous changes occur at work. Specifically, merely trying to pick up the pace and work more intensely can actually harm teams' creative processes and creative performance. Rather, teams may want to take a few moments and strategize on how they can now deal with the unexpected and uncontrollable change in order to successfully have effective team performance. Therefore, merely working more intensely is not always the correct approach, and as we saw in these two studies, doing this can actually be a maladaptive response to exogenous change across different types of changes.

There are a few limitations to this research that should be noted. First, because our methods only considered overall deviations in pacing and not the specific order and direction of these changes, we were unable to evaluate how different types of changes (e.g., magnitude, sequence) might result from unanticipated change, and in turn, how they might affect team process and performance. For instance, in Study 1 the change caused teams to rapidly increase their pace, while in Study 2, the change caused teams to decrease and then increase their pace. Therefore, future research should explore the direction, magnitude, and sequence of these changes in pace. Furthermore, the two studies reported here examined the work process of teams engaged in a short term project in the behavioral laboratory. While there is quite a bit of evidence that results from the laboratory generalize very well to the field (e.g., Locke, 1986), future research should examine these issues using longer term field projects. Finally, in this study we 
only considered hastened deadlines and additional workload, not their counters. We chose this focus because changes that constrain teams' resources and increase their workload are more common in dynamic organizations. However, future research also should examine the role of pacing deviations when deadlines are extended or workload specifications are decreased, to see if there are different results under these conditions.

In conclusion, in today's dynamic business environment, understanding how teams are affected by and adapt to an unexpected exogenous change is important. In these two studies, we found that teams' pattern of task pacing can be maladaptive in response to an exogenous change, undermining effective teams' creative processes and subsequently harming teams' creative performance. Furthermore, the timing of when these unexpected changes are introduced in their work process can have a significant impact on the teams' ability to adapt their task pacing, as well as their creative processes and performance. 


\section{References}

Amabile, T. M. (1983). The social psychology of creativity: A componential conceptualization. Journal of Personality and Social Psychology, 45(2), 357-376.

Baard, S. K., Rench, T. A., \& Kozlowski, S. W. (2014). Performance adaptation: A theoretical integration and review. Journal of Management, 40(1), 48-99.

Baer, M., \& Oldham, G. R. (2006). The curvilinear relation between experienced creative time pressure and creativity: Moderating effects of openness to experience and support for creativity. Journal of Applied Psychology, 91(4), 963-970.

Ballard, D. I., Tschan, F., \& Waller, M. J. (2008). All in the timing considering time at multiple stages of group research. Small Group Research, 39(3), 328-351.

Blount, S., \& Janicik, G. A. (2001). When plans change: Examining how people evaluate timing changes in work organizations. Academy of Management Review, 26(4), 566-585.

Bluedorn, A. C., \& Jaussi, K. S. (2008). Leaders, followers, and time. The Leadership Quarterly, 19(6), 654-668.

Bowers, C. A., Braun, C. C., \& Morgan, B. B. (1997). Team workload: Its meaning and measurement. In M. T. Brannick, E. Salas, \& C. Price (Eds.), Team Performance Assessment and Measurement: Theory, Methods, and Applications (pp. 85-108).

Hillsdale, NJ: Lawrence Erlbaum.

Chang, A., Bordia, P., \& Duck, J. (2003). Punctuated equilibrium and linear progression: Toward a new understanding of group development. Academy of Management Journal, 46(1), 106117. 
Chun, W. Y., \& Kruglanski, A. W. (2006). The role of task demands and processing resources in the use of base-rate and individuating information. Journal of Personality and Social Psychology, 91(2), 205-217.

Eisenhardt, K. M. (1989). Making fast strategic decisions in high-velocity environments. Academy of Management Journal, 32(3), 543-576.

Fine, C. H. (1998). Clockspeed: Winning industry control in the age of temporary advantage. New York: Perseus.

Fisher, C. D. (1984). Laboratory experimentation. In T.S. Bateman \& G. R Ferris (Eds.), Method and Analysis in Organizational Research (pp. 169-185). Reston, VA: Reston Publishing.

Gardner, H. K., Gino, F., \& Staats, B. R. (2012). Dynamically integrating knowledge in teams: Transforming resources into performance. Academy of Management Journal, 55(4), 9981022.

Gersick, C. J. (1988). Time and transition in work teams: Toward a new model of group development. Academy of Management Journal, 31(1), 9-41.

Gersick, C. J. (1989). Marking time: Predictable transitions in task groups. Academy of Management Journal, 32(2), 274-309.

Gersick, C. J. (1994). Pacing strategic change: The case of a new venture. Academy of Management Journal, 37(1), 9-45.

Gersick, C.J., \& Hackman, J. R. (1990). Habitual routines in task-performing groups. Organizational Behavior and Human Decision Processes, 47(1), 65-97.

Harrison, D. A., Mohammed, S., McGrath, J. E., Florey, A. T., \& Vanderstoep, S. W. (2003). Time matters in team performance: Effects of member familiarity, entrainment, and task discontinuity on speed and quality. Personnel Psychology, 56(3), 633-669. 
Hayes, A. F. (2009). Beyond Baron and Kenny: Statistical mediation analysis in the new millennium. Communication Monographs, 76(4), 408-420.

Hayes, A. F. (2013). Introduction to mediation, moderation, and conditional process analysis: A regression-based approach. New York: Guilford Press.

Huey, B. M., \& Wickens, C. D. (1993). Workload transition: Implications for individual and team performance. Washington, DC: National Academies Press.

Jansen, K. J., \& Kristof-Brown, A. L. (2005). Marching to the beat of a different drummer: Examining the impact of pacing congruence. Organizational Behavior and Human Decision Processes, 97(2), 93-105.

Janssen, O. (2001). Fairness perceptions as a moderator in the curvilinear relationships between

job demands, and job performance and job satisfaction. Academy of Management Journal, 44(5), 1039-1050.

Karau, S. J., \& Kelly, J. R. (1992). The effects of time scarcity and time abundance on group performance quality and interaction process. Journal of Experimental Social Psychology, $28(6), 542-571$.

Knight, A. P. (2013). Mood at the midpoint: Affect and change in exploratory search over time in teams that face a deadline. Organization Science, 26(1), 99-118.

LePine, J. A. (2003). Team adaptation and postchange performance: effects of team composition in terms of members' cognitive ability and personality. Journal of Applied Psychology, $88(1), 27-39$

LePine, J. A. (2005). Adaptation of teams in response to unforeseen change: effects of goal difficulty and team composition in terms of cognitive ability and goal orientation. Journal of Applied Psychology, 90(6), 1153-1167. 
LePine, J. A., Colquitt, J. A., \& Erez, A. (2000). Adaptability to changing task contexts: Effects of general cognitive ability, conscientiousness, and openness to experience. Personnel Psychology, 53(3), 563-593.

Lewis, K. (2003). Measuring transactive memory systems in the field: scale development and validation. Journal of Applied Psychology, 88(4), 587-604.

Lewis, K., Belliveau, M., Herndon, B., \& Keller, J. (2007). Group cognition, membership change, and performance: Investigating the benefits and detriments of collective knowledge. Organizational Behavior and Human Decision Processes, 103(2), 159-178.

Lim, S. G.S., \& Murnighan, J. K. (1994). Phases, deadlines, and the bargaining process. Organizational Behavior and Human Decision Processes, 58(2), 153-171.

Locke, E. A. (1986). Generalizing from laboratory to field: Ecological validity or abstraction of essential elements. In E.A. Locke (Ed.), Generalizing from laboratory to field settings (pp. 3-9). Lexington, MA: Lexington Books.

Marks, M. A., Mathieu, J. E., \& Zaccaro, S. J. (2001). A temporally based framework and taxonomy of team processes. Academy of Management Review, 26(3), 356-376.

Okhuysen, G. A. (2001). Structuring change: Familiarity and formal interventions in problemsolying groups. Academy of Management Journal, 44(4), 794-808.

Okhuysen, G. A., \& Eisenhardt, K. M. (2002). Integrating knowledge in groups: How formal interventions enable flexibility. Organization Science, 13(4), 370-386.

Okhuysen, G. A., \& Waller, M. J. (2002). Focusing on midpoint transitions: An analysis of boundary conditions. Academy of Management Journal, 45(5), 1056-1065.

Orlikowski, W. J., \& Yates, J. (2002). It's about time: Temporal structuring in organizations. Organization Science, 13(6), 684-700. 
Parks, C. D., \& Cowlin, R. A. (1996). Acceptance of uncommon information into group discussion when that information is or is not demonstrable. Organizational Behavior and Human Decision Processes, 66(3), 307-315.

Porter, C. O., Webb, J. W., \& Gogus, C. I. (2010). When goal orientations collide: Effects of learning and performance orientation on team adaptability in response to workload imbalance. Journal of Applied Psychology, 95(5), 935-943.

Preacher, K. J., Rucker, D. D., \& Hayes, A. F. (2007). Addressing moderated mediation hypotheses: Theory, methods, and prescriptions. Multivariate Behavioral Research, $42(1), 185-227$.

Randall, K. R., Resick, C. J., \& DeChurch, L. A. (2011). Building team adaptive capacity: The roles of sensegiving and team composition. Journal of Applied Psychology, 96(3), 525.

Rico, R., Sánchez-Manzanares, M., Gil, F., \& Gibson, C. (2008). Team implicit coordination processes: A team knowledge-based approach. Academy of Management Review, 33(1), $163-184$.

Salvucci, D. D., \& Taatgen, N. A. (2008). Threaded cognition: An integrated theory of concurrent multitasking. Psychological Review, 115(1), 101-130.

Shalley, C. E., \& Perry-Smith, J. E. (2008). The emergence of team creative cognition: The role of diverse outside ties, sociocognitive network centrality, and team evolution. Strategic Entrepreneurship Journal, 2(1), 23-41.

Shalley, C. E., Zhou, J., \& Oldham, G. R. (2004). The effects of personal and contextual characteristics on creativity: Where should we go from here? Journal of Management, 30(6), 933-958. 
Waller, M. J. (1999). The timing of adaptive group responses to nonroutine events. Academy of Management Journal, 42(2), 127-137.

Waller, M. J., Zellmer-Bruhn, M. E., \& Giambatista, R. C. (2002). Watching the clock: Group pacing behavior under dynamic deadlines. Academy of Management Journal, 45(5), $1046-1055$.

Woolley, A. W. (2009). Means vs. ends: Implications of process and outcome focus for team adaptation and performance. Organization Science, 20(3), 500-515.

Yuan, F., \& Woodman, R. W. (2010). Innovative behavior in the workplace: The role of performance and image outcome expectations. Academy of Management Journal, 53(2), $323-342$.

Zhang, X., \& Bartol, K. M. (2010). Linking empowering leadership and employee creativity: The influence of psychological empowerment, intrinsic motivation, and creative process engagement. Academy of Management Journal, 53(1), 107-128.

Zijlstra, F. R., Waller, M. J., \& Phillips, S. I. (2012). Setting the tone: Early interaction patterns in swift-starting teams as a predictor of effectiveness. European Journal of Work and Organizational Psychology, 21(5), 749-777.

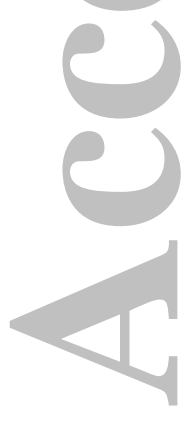


Table 1

Study 1 Descriptive Statistics

\begin{tabular}{|c|c|c|c|c|c|c|}
\hline GROUP & 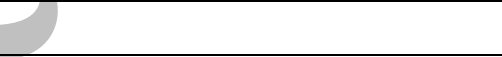 & $\mathrm{N}$ & Mean & SD & Minimum & Maximum \\
\hline \multirow{7}{*}{ 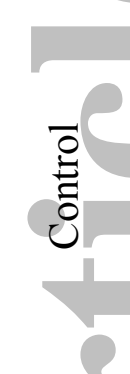 } & Team creative performance & 14 & 4.78 & 0.85 & 3.33 & 5.89 \\
\hline & Pacing 0-5 minutes & 14 & 5.36 & 0.57 & 4.00 & 6.00 \\
\hline & Pacing 5-10 minutes & 14 & 5.54 & 0.75 & 3.50 & 6.50 \\
\hline & Pacing 10-15 minutes & 14 & 5.50 & 1.14 & 2.00 & 6.00 \\
\hline & Pacing 15-20 minutes & 14 & 5.07 & 1.22 & 1.50 & 6.00 \\
\hline & Deviating patterns of pacing & 14 & 0.61 & 0.52 & 0.15 & 2.12 \\
\hline & Time pressure & 14 & 4.99 & 0.70 & 3.61 & 6.48 \\
\hline \multirow{9}{*}{ 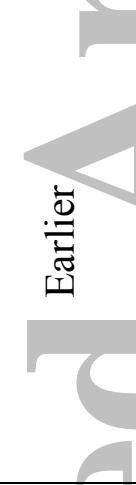 } & Team creative performance & 18 & 4.69 & 0.53 & 3.67 & 5.56 \\
\hline & Pacing 0-5 minutes & 18 & 5.50 & 0.69 & 3.00 & 6.00 \\
\hline & Pacing 5-10 minutes & 18 & 5.56 & 0.59 & 3.50 & 6.00 \\
\hline & Pacing 10-15 minutes & 18 & 5.44 & 0.70 & 3.50 & 6.00 \\
\hline & Pacing 15-20 minutes & 18 & 5.31 & 1.27 & 1.00 & 6.50 \\
\hline & Deviating patterns of pacing & 18 & 0.53 & 0.39 & 0.06 & 1.56 \\
\hline & Creative process before disruption & 18 & 4.28 & 0.87 & 2.50 & 6.00 \\
\hline & Creative process after disruption & 18 & 4.58 & 0.69 & 3.00 & 5.50 \\
\hline & Time pressure & 18 & 4.68 & 0.96 & 3.22 & 6.43 \\
\hline \multirow{9}{*}{$\frac{\Xi}{0} \frac{0}{0}$} & Team creative performance & 20 & 4.69 & 0.73 & 3.67 & 6.11 \\
\hline & Pacing 0-5 minutes & 20 & 5.65 & 0.56 & 4.50 & 6.50 \\
\hline & Pacing 5-10 minutes & 20 & 5.55 & 0.74 & 3.00 & 6.50 \\
\hline & Pacing 10-15 minutes & 20 & 5.55 & 0.72 & 3.50 & 6.50 \\
\hline & Pacing 15-20 minutes & 20 & 5.28 & 1.37 & 1.00 & 6.50 \\
\hline & Deviating patterns of pacing & 20 & 0.64 & 0.48 & 0.15 & 2.37 \\
\hline & Creative process before disruption & 20 & 4.38 & 0.66 & 3.10 & 5.80 \\
\hline & Creative process after disruption & 20 & 4.34 & 0.85 & 2.70 & 5.50 \\
\hline & Time pressure & 20 & 4.50 & 0.56 & 3.10 & 5.29 \\
\hline & Team creative performance & 20 & 4.08 & 0.56 & 3.11 & 5.11 \\
\hline & Pacing 0-5 minutes & 20 & 5.53 & 0.64 & 3.50 & 6.50 \\
\hline & Pacing 5-10 minutes & 20 & 5.18 & 0.75 & 3.50 & 6.50 \\
\hline & Pacing 10-15 minutes & 20 & 4.78 & 1.23 & 1.00 & 6.00 \\
\hline & Pacing 15-20 minutes & 20 & 5.15 & 0.92 & 3.00 & 6.00 \\
\hline & Deviating patterns of pacing & 20 & 0.71 & 0.46 & 0.15 & 1.99 \\
\hline & Creative process before disruption & 20 & 4.23 & 0.76 & 2.10 & 5.60 \\
\hline & Creative process after disruption & 20 & 3.63 & 1.19 & 1.10 & 5.40 \\
\hline & Time pressure & 20 & 4.46 & 0.91 & 2.9 & 5.99 \\
\hline
\end{tabular}


Table 2

Study 2 Descriptive Statistics

\begin{tabular}{|c|c|c|c|c|c|c|}
\hline & 1 & $\mathrm{~N}$ & Mean & SD & Minimum & Maximum \\
\hline \multirow{7}{*}{$\begin{array}{l}\text { OO } \\
\stackrel{\Xi}{0} \\
\text { Ȯ }\end{array}$} & Team creativity & 15.00 & 4.70 & 0.73 & 3.00 & 5.61 \\
\hline & Pacing 0-5 minutes & 15.00 & 3.82 & 0.36 & 2.75 & 4.50 \\
\hline & Pacing 5-10 minutes & 15.00 & 3.90 & 0.16 & 3.75 & 4.25 \\
\hline & Pacing 10-15 minutes & 15.00 & 3.95 & 0.29 & 3.50 & 4.50 \\
\hline & Pacing 15-20 minutes & 15.00 & 3.95 & 0.22 & 3.75 & 4.25 \\
\hline & Deviating patterns of pacing & 15.00 & 0.19 & 0.08 & 0.10 & 0.39 \\
\hline & Time pressure & 15.00 & 3.94 & 0.80 & 2.50 & 5.05 \\
\hline \multirow{9}{*}{ 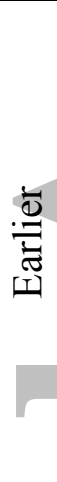 } & Team creativity & 19.00 & 4.32 & 0.82 & 2.78 & 6.00 \\
\hline & Pacing 0-5 minutes & 19.00 & 3.83 & 0.19 & 3.50 & 4.25 \\
\hline & Pacing 5-10 minutes & 19.00 & 3.90 & 0.21 & 3.50 & 4.75 \\
\hline & Pacing 10-15 minutes & 19.00 & 3.90 & 0.24 & 3.25 & 4.25 \\
\hline & Pacing 15-20 minutes & 19.00 & 3.90 & 0.31 & 3.25 & 4.75 \\
\hline & Deviating patterns of pacing & 19.00 & 0.17 & 0.10 & 0.07 & 0.40 \\
\hline & Creative process before disruption & 19.00 & 4.36 & 0.91 & 2.50 & 5.70 \\
\hline & Creative process after disruption & 19.00 & 4.85 & 0.81 & 3.20 & 6.30 \\
\hline & Time pressure & 19.00 & 4.27 & 0.87 & 2.72 & 5.95 \\
\hline \multirow{9}{*}{ 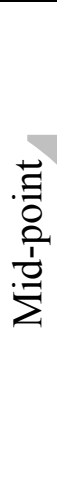 } & Team creativity & 19.00 & 3.60 & 0.70 & 1.94 & 4.78 \\
\hline & Pacing 0-5 minutes & 19.00 & 3.84 & 0.27 & 3.50 & 4.50 \\
\hline & Pacing 5-10 minutes & 19.00 & 4.00 & 0.33 & 3.25 & 4.75 \\
\hline & Pacing 10-15 minutes & 19.00 & 3.80 & 0.47 & 2.50 & 4.75 \\
\hline & Pacing 15-20 minutes & 19.00 & 3.93 & 0.29 & 3.50 & 4.50 \\
\hline & Deviating patterns of pacing & 19.00 & 0.27 & 0.12 & 0.12 & 0.52 \\
\hline & Creative process before disruption & 19.00 & 4.48 & 1.25 & 2.40 & 6.50 \\
\hline & Creative process after disruption & 19.00 & 4.07 & 0.92 & 2.40 & 5.50 \\
\hline & Time pressure & 19.00 & 3.90 & 0.91 & 2.22 & 5.44 \\
\hline \multirow{9}{*}{ 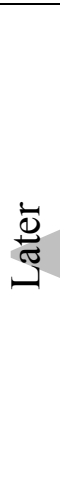 } & Team creativity & 18.00 & 3.80 & 0.87 & 2.22 & 5.56 \\
\hline & Pacing 0-5 minutes & 18.00 & 3.83 & 0.30 & 2.75 & 4.50 \\
\hline & Pacing 5-10 minutes & 18.00 & 3.97 & 0.37 & 3.25 & 5.00 \\
\hline & Pacing 10-15 minutes & 18.00 & 4.13 & 0.35 & 3.75 & 5.00 \\
\hline & Pacing 15-20 minutes & 18.00 & 3.88 & 0.28 & 3.25 & 4.25 \\
\hline & Deviating patterns of pacing & 18.00 & 0.24 & 0.11 & 0.07 & 0.48 \\
\hline & Creative process before disruption & 18.00 & 4.77 & 1.05 & 2.50 & 6.10 \\
\hline & Creative process after disruption & 18.00 & 4.18 & 0.74 & 2.60 & 5.20 \\
\hline & Time pressure & 18.00 & 3.82 & 1.05 & 0.67 & 5.22 \\
\hline
\end{tabular}


Figure 1

Study 1 Pacing in the Control and the Later Conditions

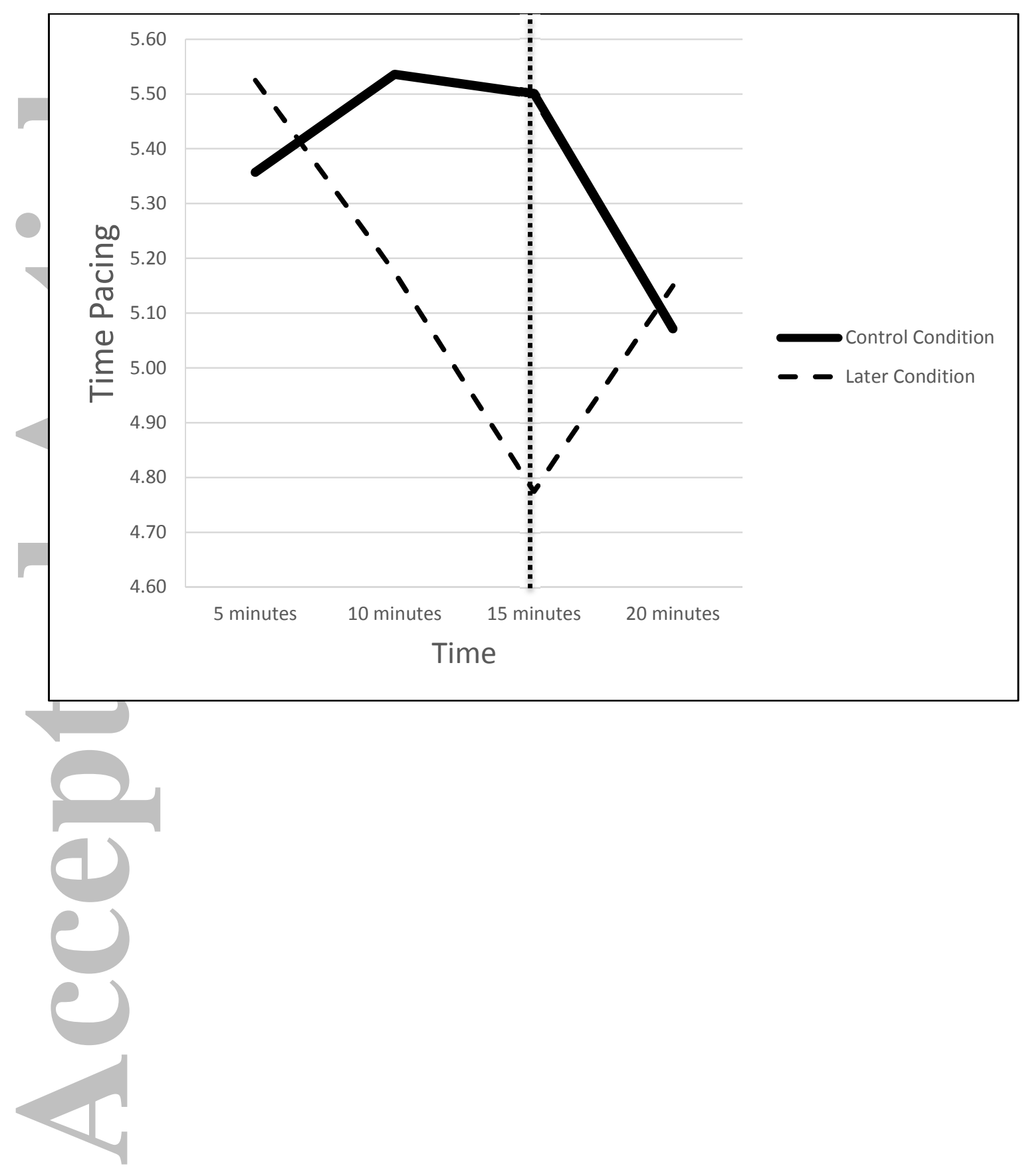

Journal of Applied Social Psychology

This article is protected by copyright. All rights reserved. 
Figure 2

Study 2 Pacing in the Control and the Midpoint Conditions

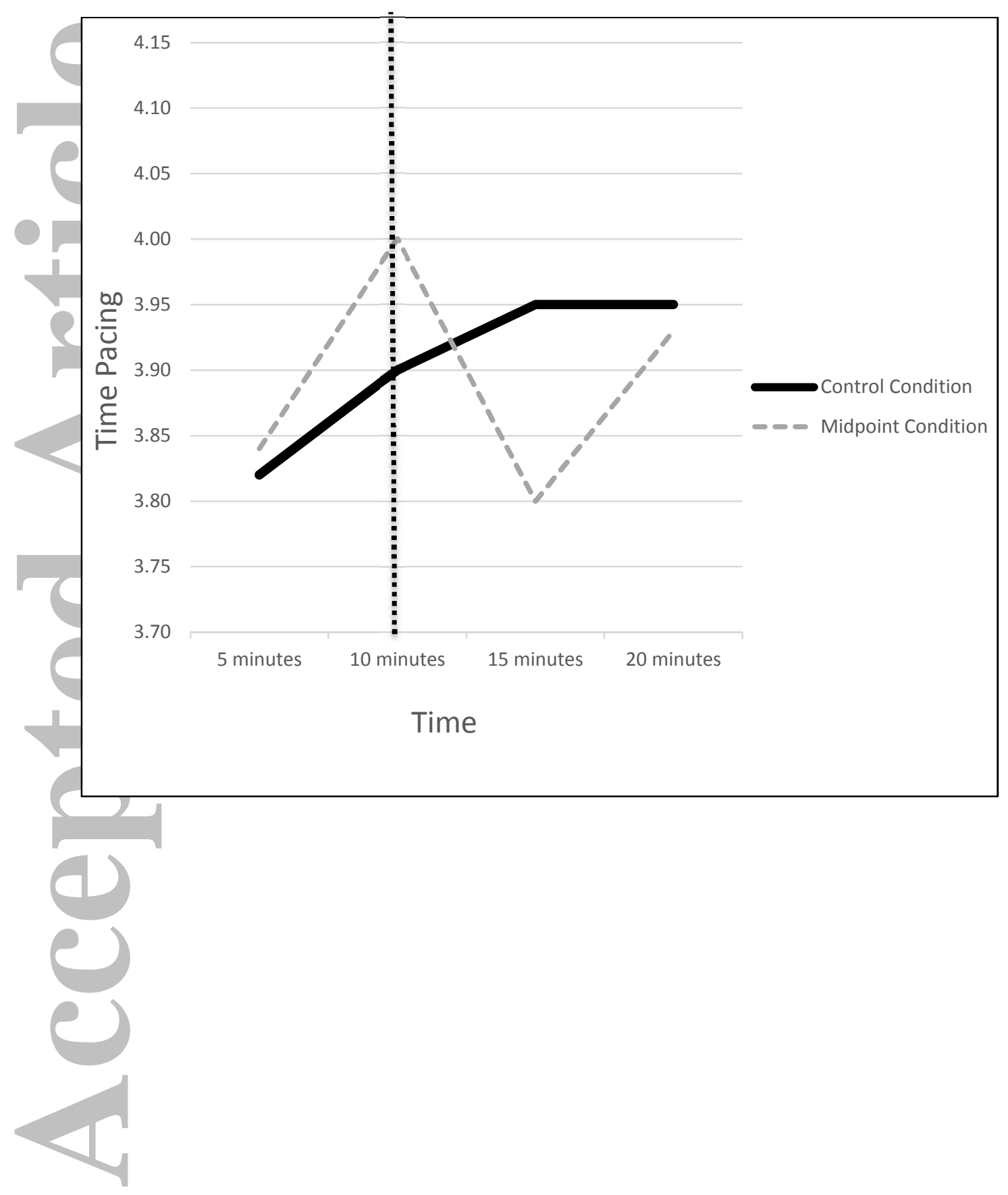

51

Journal of Applied Social Psychology

This article is protected by copyright. All rights reserved. 
Figure 3

Study 2 Pacing in the Control and the Later Conditions

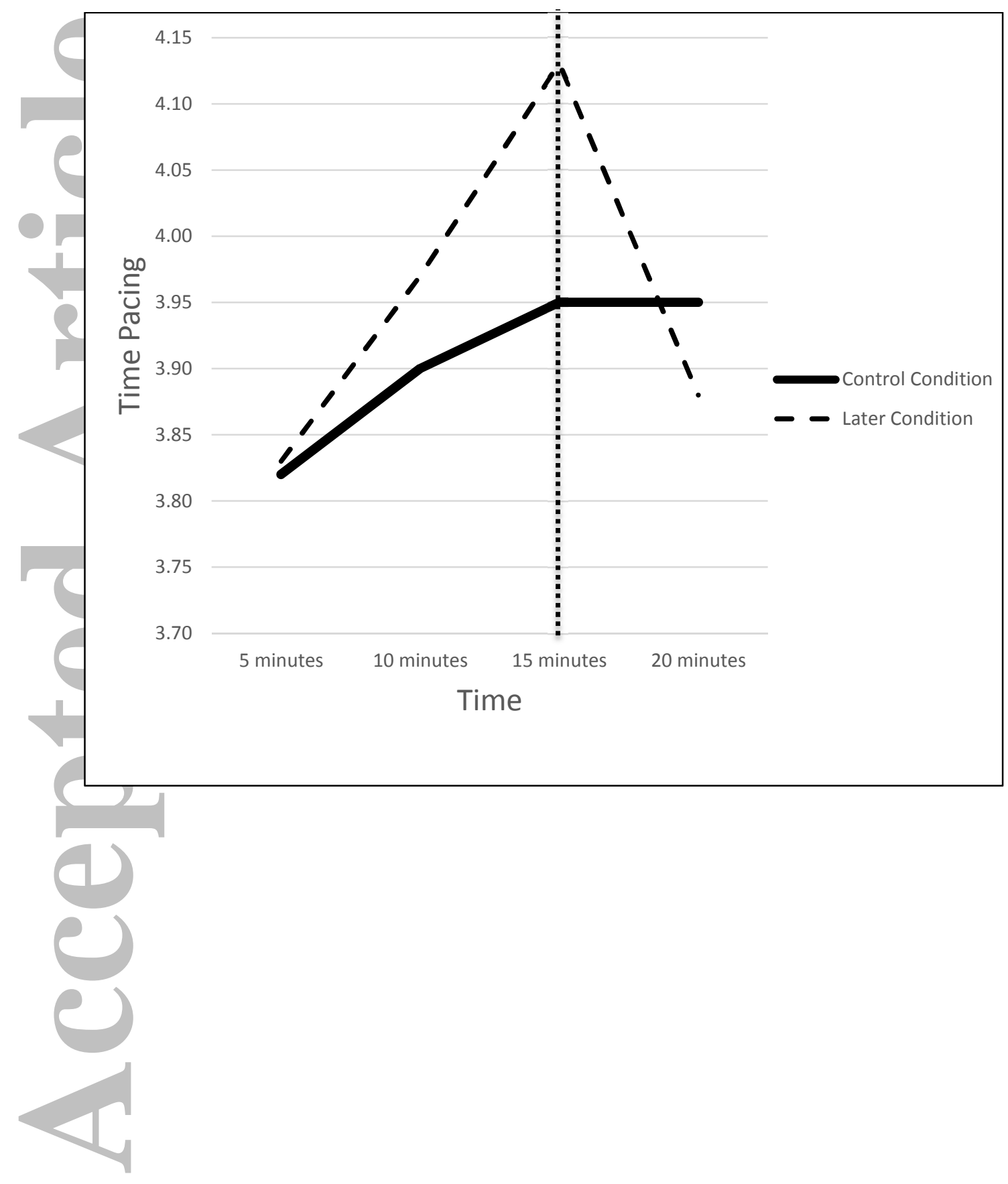

Journal of Applied Social Psychology

This article is protected by copyright. All rights reserved. 


\section{University Library}

\section{- M M I N E R VA A gateway to Melbourne's research publications}

Minerva Access is the Institutional Repository of The University of Melbourne

Author/s:

Koseoglu, G;Shalley, CE;Herndon, B

Title:

Task context changes: teams' maladaptive responses to unanticipated change

Date:

2017-04-01

Citation:

Koseoglu, G., Shalley, C. E. \& Herndon, B. (2017). Task context changes: teams' maladaptive responses to unanticipated change. JOURNAL OF APPLIED SOCIAL PSYCHOLOGY, 47 (4), pp.195-212. https://doi.org/10.1111/jasp.12424.

Persistent Link:

http://hdl.handle.net/11343/292247 